\title{
Early Retinal and Choroidal Coat Thickness Changes after Intravitreal Dexamethasone Implant Injection for Diabetic Macular Edema
}

\author{
Fatih Horozoğlu, Özkan Sever
}

Department of Ophthalmology, Namık Kemal University School of Medicine, Tekirdağ, Turkey

Background: Intravitreal steroid injection is one of the treatment options for diabetic macular edema. Dexamethasone implant is the most novel form of intravitreal steroid therapy. Improvement in macular thickness is a well-known effect of Dexamethasone implant however, subfoveal choroidal coat thickness changes require investigation.

Aims: To evaluate the early central macular thickness and subfoveal choroidal thickness alterations after single-dose dexamethasone implant injection in diabetic macular edema.

Study Design: Cross-sectional study.

Methods: We identified 29 patients with diabetic macular edema (29 eyes) who underwent optical coherence tomography and fundus fluorescein angiography. All patients received a single-dose intravitreal Dexamethasone implant and were followed up for central macular thickness and subfoveal choroidal thickness alterations for 1 hour, 1 week, 1 month, and 3 months post-injection.

Results: The preoperative mean central macular thickness and subfoveal choroidal thickness measurements were $592.3 \pm 122.3$ (412-879) $\mu \mathrm{m}$ and $264.8 \pm 53.7$ (165-397) $\mu \mathrm{m}$, respectively. Central macular thickness measurements decreased significantly in the first hour $(p<0.050)$ and continued to decrease until the third month $(p<0.001)$, whereas the subfoveal choroidal thickness decrement was only significant on the first day $(\mathrm{p}<0.05)$. Decreases in subfoveal choroidal thickness and central macular thickness of $1.5 \%$ and $5 \%$ were observed at 1 hour; however, the difference was not significant $(p>0.050)$. The decrease in central macular thickness was significantly greater than that in subfoveal choroidal thickness at 1 day, 1 week, 1 month, and 3 months $(\mathrm{p}<0.001)$.

Conclusion: Intravitreal Dexamethasone implant has a meaningful effect on central macular thickness in patients with diabetic macular edema, while subfoveal choroidal thickness decreases significantly at first day.

Keywords: Choroidal coat, Dexamethasone, diabetes mellitus, macular edema
Diabetic macular edema (DME) is the major cause of vision loss in patients with diabetes (1). Laser photocoagulation, anti-vascular endothelial growth factor (anti-VEGF) injections, corticosteroid injections and pars plana vitrectomy are among the previously used treatment modalities (2-5). The effects of anti-angiogenesis and decreasing vascular permeability makes VEGF a logical target in the treatment of diabetic macular edema. While anti-VEGF treatment has a positive effect on visual improvement in diabetic macular edema, there have been several limitations to its use, such as the need for multiple injections and, in some patients, anti-VEGF treatment is not successful (6). Fluocinolone (Iluvien ${ }^{\circledR}$, Alimera) and Dexamethasone (Dx) implant (Ozurdex ${ }^{\circledR}$, Allergan) are the approved corticosteroid therapies for the treatment of diabetic macular edema $(7,8)$. Although anti-VEGF treatment improves visual acuity, it requires monthly injections. Dx implant was able improve vision by 4 letters with fewer injections compared with anti-VEGF agents (7). Changes in central macular thickness and subfoveal choroidal thickness before and after drug injection have been of interest since the invention of optical coherence tomography in recent years $(9,10)$. Favorable results were obtained with Dx implant treatment in anti-VEGF-resistant eyes with diabetic macular edema and there was a correlation between the reductions in central macular thickness and subfoveal choroidal thickness (11). In this study, we aimed to investigate early choroidal and macular thickness changes after the injection of Dx implant.

\section{MATERIALS AND METHODS}

This cross-sectional study was conducted in accordance with the Declaration of Helsinki on patients with diabetic macular edema who received intravitreal Dx implant (Ozurdex ${ }^{\circledR}$; Allergan, Irvine, California, USA) (7) over the period of May 2014 to June 2016. Best-corrected visual acuity (BCVA) with a Snellen chart, biomicroscopic evaluation with a slit-lamp, intraocular pressure measurement with tonometry, and fundus examination with a

This study has been presented in part as a poster in the $16^{\text {th }}$ Retina Academy 2016 at 23-25 June 2016 in Portugal.

Address for Correspondence: Dr. Fatih Horozoğlu, Department of Ophthalmology, Namık Kemal University School of Medicine, Tekirdağ, Turkey

Phone: +905336533650 e-mail: fhoroz@yahoo.com ORCID ID: orcid.org/0000-0002-1442-6032

Received: 3 August $2017 \quad$ Accepted: 24 May 2018 •DOI: 10.4274/balkanmedj.2017.1013

Available at www.balkanmedicaljournal.org

Cite this article as:

Horozoğlu F, Sever Ö. Early Retinal and Choroidal Coat Thickness Changes after Intravitreal Dexamethasone Implant Injection for Diabetic Macular Edema. Balkan Med J 2018;35:384-7

${ }^{\circ}$ Copyright 2018 by Trakya University Faculty of Medicine / The Balkan Medical Journal published by Galenos Publishing House. 
$78 \mathrm{D}$ lens were the used as the standard ocular examination for all patients at the first visit. Fundus fluorescein angiography and optical coherence tomography evaluations were performed before treatment.

\section{Ethics}

The Institutional Ethics Committee approved the study protocol. The risks of surgical treatment were explained to all patients, and informed consent was obtained.

\section{Optical coherence tomography measurements}

Macular thickness was measured by spectral domain optical coherence tomography (Cirrus $\mathrm{HD}^{\mathrm{TM}}$, Carl Zeiss Meditec) with the machine's own software protocol as the distance between the internal limiting membrane and the retinal pigment epithelium. Raster mode was used to scan the fovea with 1024 A-scans per line. The enhanced depth imaging (EDI-optical coherence tomography) mode of Cirrus $\mathrm{HD}^{\mathrm{TM}}$ was used for subfoveal choroidal thickness evaluation between retinal pigment epithelium and the internal scleral border from the thinnest zone corresponding fovea. Manual measurement was performed with a digital caliper by a technician who was blinded to treatment. Subfoveal choroidal thickness measurement of a patient is shown in Figure 1. Macular edema was defined as a central macular thickness $\geq 300 \mu \mathrm{m}$.

\section{Patients}

Eyes that met the following criteria were excluded: 1) vitreous hemorrhage or cataract-like media opacities, 2) foveal avascular zone irregularities detected by Fundus fluorescein angiography, 3 ) six clock hours or more of macular capillary non-perfusion on Fundus fluorescein angiography, 4) any neovascularizations, 5) history of vitreoretinal surgery, or 6) preoperative vitreomacular interface disease detected by optical coherence tomography. The Dx implant was injected intravitreally to all patients, and patients were examined for central macular thickness and subfoveal choroidal thickness changes 1 hour, 1 day, 1 week, 1 month, and 3 months postoperatively. Following Ozurdex ${ }^{\circledR}$ implantation, measurement of BCVA, slit-lamp biomicroscopy, fundus examination by $78 \mathrm{D}$ lens, tonometry and optical coherence tomography evaluation were repeated at each visit.

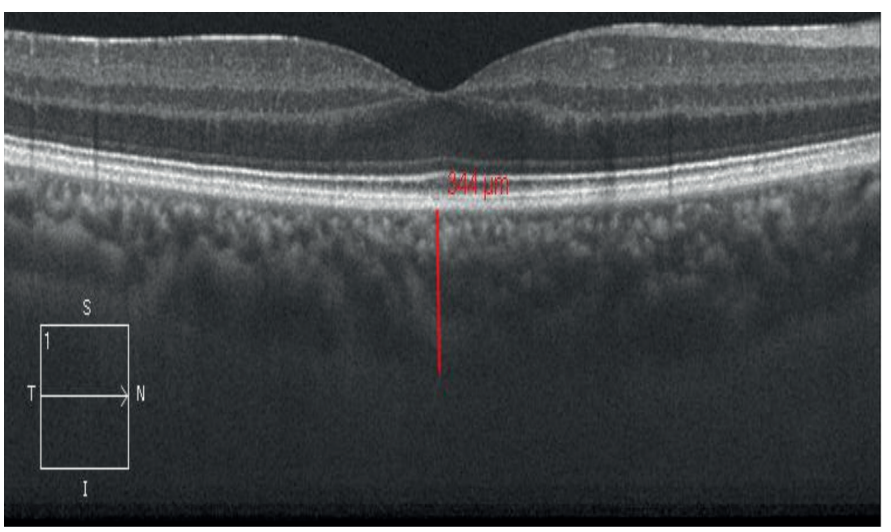

FIG. 1. Subfoveal choroidal thickness measurement of a patient who had received intravitreal Dexamethasone implant $\left(\right.$ Ozurdex $\left.^{\circledR}\right)$.

\section{Statistical analysis}

The program PASW Statistics 18 was used to analyze the results. Percentage was used for qualitative data and mean \pm standard deviation, for quantitative data. Treatment effectiveness was evaluated for each patient by comparing pre- and post-injection subfoveal choroidal thickness and central macular thickness at each visit by paired-sample t-test. Subfoveal choroidal thickness and central macular thickness groups were compared by independentsample t-test. Statistical values of $\mathrm{p}<0.05$ were accepted as significant.

The program $G$ power 3.1 was used to calculate the sample size and power. In a choroidal and macular thickness calculation repeated five times with $n=29$, if the probability of a type 1 error $(\alpha)=0.05$, the partial Eta squared was 0.212 and 0.795 , the correction for nonsphericity $\varepsilon$ was 0.25 and 0.446 , the power was $75.47 \%$ and $100 \%$, respectively.

\section{RESULTS}

We identified 29 patients with diabetic macular edema (29 eyes) who underwent single-dose Dx implant injection. Of the 29 patients, 16 were female and 13 were male. Table 1 shows the baseline patient characteristics. The mean number of previous antiVEGF injections was 1.55 (0 to 6). Preoperative and postoperative central macular thickness and subfoveal choroidal thickness changes are listed in Table 2.

Preoperative mean thickness was $592.3 \pm 122.3(412-879) \mu \mathrm{m}$ in central macular thickness and 264.8 \pm 53.7 (165-397) in subfoveal choroidal thickness. Table 2 shows preoperative and postoperative central macular thickness and subfoveal choroidal thickness measurements. Measurements taken for central macular thickness at 1 hour, 1 day, 1 week, 1 month, and 3 months after Dx implantation. As we compare the change between the preoperative and post-injection values, all of them were significantly decreased $(\mathrm{p}<0.050)$. However, the decrement in subfoveal choroidal thickness from preoperative values was only significant at 1 day postoperatively $(\mathrm{p}<0.050)$. Table 3 shows a comparison of the differences in central macular thickness and subfoveal choroidal thickness. Decreases in subfoveal choroidal thickness and central macular thickness of $1.5 \%$ and $5 \%$ were observed at 1 hour; however, the difference was not significant $(\mathrm{p}>0.050)$. The decrease in central macular thickness was significantly greater than

TABLE 1. Patient characteristics

\begin{tabular}{lc}
\hline Sex, $\mathrm{n}$ & 29 \\
Male & 13 \\
Female & 16 \\
Follow-up & 1 hour-3 month \\
Previous anti-VEGF injections, mean (range) & $1.55(0-6)$ \\
Previous laser photocoagulation, $\mathrm{n}$ & 14 \\
Age & \\
Mean \pm standard deviation & $58.2 \pm 12.2$ \\
Range & $54-76$ \\
\hline VEGF: vascular endothelial growth factor & \\
\hline
\end{tabular}


that in subfoveal choroidal thickness at 1 day, 1 week, 1 month, and 3 months $(\mathrm{p}<0.001)$.

TABLE 2. Central macular thickness and subfoveal choroidal thickness changes after single-dose intravitreal Dexamethasone implant

\begin{tabular}{lccc}
\hline & Changes, (percent) & $\begin{array}{c}\text { Mean } \pm \text { standard } \\
\text { deviation }(\mu \mathrm{m})\end{array}$ & p values* \\
\hline SFCT $(\mu \mathrm{m})$ & & \\
Preoperative & & $264 \pm 53$ & 0.089 \\
1 hour & $-4 \pm 13$ & $260 \pm 49$ & 0.042 \\
1 day & $-10 \pm 25$ & $254 \pm 42$ & 0.973 \\
1 week & $0.3 \pm 48$ & $265 \pm 38$ & 0.651 \\
1 month & $-6 \pm 66$ & $259 \pm 43$ & 0.816 \\
3 months & $-3 \pm 63$ & $262 \pm 38$ & \\
& & & $<0.001$ \\
CMT ( $\mu \mathrm{m})$ & $-27 \pm 63$ & $592 \pm 122 \mu \mathrm{m}$ & $<0.001$ \\
Preoperative & $-100 \pm 96$ & $492 \pm 123 \mu \mathrm{m}$ & $<0.001$ \\
1 hour & $-218 \pm 112$ & $374 \pm 83 \mu \mathrm{m}$ & $<0.001$ \\
1 day & $-262 \pm 141$ & $330 \pm 95 \mu \mathrm{m}$ & $<0.001$ \\
1 week & $-268 \pm 168$ & $324 \pm 117 \mu \mathrm{m}$ & \\
1 month & & & \\
3 months & & & \\
\hline CMT: central macular thickness; SFCT: subfoveal choroidal thickness; & Paired- \\
samples t-test & & & \\
\hline
\end{tabular}

TABLE 3. Comparison of subfoveal choroidal thickness and central macular thickness changes in eyes after single-dose intravitreal Dexamethasone implant

\begin{tabular}{lc}
\hline Difference & p values $^{\mu}$ \\
\hline PreDx implant-postoperative first hour & 0.680 \\
PreDx implant-postoperative first day & $<0.001$ \\
PreDx implant-postoperative first week & $<0.001$ \\
PreDx implant-postoperative first month & $<0.001$ \\
PreDx implant-postoperative third month & $<0.001$ \\
\hline
\end{tabular}

CMT: central macular thickness; SFCT: subfoveal choroidal thickness; $\mu$ : Independent samples t-test

\section{DISCUSSION}

Evaluation of the choroid was of interest previously, and until the advent of EDI-optical coherence tomography, imaging of the choroid was performed by using indocyanine green angiography (ICGA) or laser Doppler flowmetry. Recently reported choroidal vascular abnormalities in diabetic eyes included dilatation, obstruction, non-perfusion, tortuosity increase, and remodeling (12-14). It is speculated that diabetic choroidopathy (DC) would have a role in explaining visual loss in diabetic eyes without retinopathy (15). An increase in the resistance index has been reported by laser Doppler flowmetry beneath the fovea and might be a result of progressive reduction of choroidal blood flow and volume in diabetic patients, even in eyes without retinopathy (16). These data implicate DC as a potential trigger of the development of retinopathy. Thus, ICGA and laser Doppler flowmetry can provide valuable data about the choroid, and research has been focused on increasing understanding and identifying other possible roles of the choroid. With the introduction of EDI-optical coherence tomography (17), several studies concentrated on the choroid, and much was learned about retinochoroidal diseases
$(18,19)$. Tracking changes in choroidal thickness in patients with diabetic macular edema might be useful to predict the effect of antiVEGF treatment (20). Although there are many studies evaluating subfoveal choroidal thickness as well as choroidal area in diabetic patients, there is still controversy surrounding choroidal thickness in diabetic eyes. Regatieri et al. (21) reported that patients with diabetic macular edema have thinner choroid than non-diabetic patients, whereas Kim et al. (22) revealed that subfoveal choroidal thickness increased with increasing severity of diabetic retinopathy (from no diabetic retinopathy to proliferative diabetic retinopathy) and in the presence of diabetic macular edema, especially in eyes with serous retinal detachment.

In the current study, after single-dose injection of Dx implant, subfoveal choroidal thickness decreased significantly on the first day; however, this decrease was not maintained at 1 and 3 months follow-up in eyes with diabetic macular edema. However, central macular thickness decreased beginning from the first hour after injection and continue to decrease until 3 months follow-up. Previously, mean subfoveal choroidal thickness was reported to be $280 \mu \mathrm{m}$ in a healthy Turkish population with a mean age of 47 years (23). They reported a decrease in subfoveal choroidal thickness of $3.14 \mu \mathrm{m}$ for each year of age. We found a mean subfoveal choroidal thickness of $264 \mu \mathrm{m}$ in a diabetic population with a mean age of 58 years in this study. As we compare the mean subfoveal choroidal thicknesses of population between Ozdogan Erkul et al. (23) study and our study, there is a slight decrease $(16 \mu \mathrm{m})$ in our diabetic population that might be the negative effect of previous panretinal photocoagulation. The difference between the healthy population and our diabetic population might have been caused by previous panretinal photocoagulation in some eyes, which is known to decrease subfoveal choroidal thickness (24), and the older age of our patients.

A prospective study that compared the effects of triamcinolone acetonide and bevacizumab injections on choroidal thickness in diabetic macular edema showed a significant decrease in subfoveal choroidal thickness from 24 hours to 12 weeks with triamcinolone acetonide (25). In a similar study that demonstrated changes in choroidal thickness after the injection of Dx implant in eyes with diabetic macular edema and a history of multiple injections of anti-VEGF, the decreases in subfoveal choroidal thickness and central macular thickness were similar and were significant at 1 and 3 months postoperatively (11). In this study, mean preoperative choroidal thickness was 288 microns and decreased to 260 and 266 microns after 1 and 3 months, respectively. The authors mentioned that previous anti-VEGF injections before Dx injection might have impacted on choroidal thickness measurements. As our patients were not fully included with refractory diabetic macular edema and persistent fluid despite anti-VEGF injections, this may also be a limitation of our study. We excluded eyes with PDR and active neovascularization from our study. This group of eyes is reported to have the thickest subfoveal choroidal thickness among eyes with diabetic retinopathy (22). This may explain the discrepancy between our results and those of Kim et al. (11).

Central macular thickness was decreased after injection of the Dx implant at the postoperative $1^{\text {st }}$ hour, and this decrease was maintained for 3 months. This is a well-known effect of Dx 
implant in diabetic macular edema, even in eyes with persistent fluid despite multiple anti-VEGF injections (11,26-29). Our study confirmed these results.

Manual measurement of subfoveal choroidal thickness, heterogeneous groups of patients with and without previous panretinal photocoagulation, and the variable timing of previous anti-VEGF injections were the limitations of our study. Although eyes were not divided into groups corresponding retinopathy stages, eyes with active neovascularization were not included in the study. Despite these limitations, our study is the first to report early retinal and choroidal thickness changes as well as their correlations in diabetic patients who received Dx implant.

In conclusion, this study concentrated on early effects of Dx implant on subfoveal choroidal thickness and compared the changes in subfoveal choroidal thickness and central macular thickness. Dx implant is found to be effective at decreasing macular edema in diabetic eyes for up to 3 months. However, subfoveal choroidal thickness exhibited a significant decrease only on the first day after Dx implant injection. A comparison of subfoveal choroidal thickness and central macular thickness changes did not reveal a significant difference. The effect of Dx implant on choroidal thickness still is uncertain. Further studies enabling non-invasive visualization of vascular structures with optical coherence tomography angiography and other techniques will identify the effects of injections on the retina and choroid in diabetic macular edema.

Conflict of Interest: No conflict of interest was declared by the authors.

Financial Disclosure: No financial disclosure was declared by the authors.

\section{REFERENCES}

1. Moss SE, Klein R, Klein BE. The 14-year incidence of visual loss in a diabetic population. Ophthalmology 1998;105:998-1003.

2. No authors listed. Photocoagulation for diabetic macular edema. Early Treatment Diabetic Retinopathy Study report number 1. Early Treatment Diabetic Retinopathy Study research group. Arch Ophthalmol 1985;103:1796-806.

3. Chun DW, Heier JS, Topping TM, Duker JS, Bankert JM. A pilot study of multiple intravitreal injections of ranibizumab in patients with center-involving clinically significant diabetic macular edema. Ophthalmology 2006;113:1706-12.

4. Callanan DG, Gupta S, Boyer DS, Ciulla TA, Singer MA, Kuppermann BD, et al. Dexamethasone intravitreal implant in combination with laser photocoagulation for the treatment of diffuse diabetic macular edema. Ophthalmology 2013;120:1843-51.

5. Yanyali A, Horozoglu F, Celik E, Nohutcu AF. Long-term outcomes of pars plana vitrectomy with internal limiting membrane removal in diabetic macular edema. Retina 2007;27:557-66.

6. Bressler SB, Qin H, Beck RW, Chalam KV, Kim JE, Melia M, Wells JA 3rd; Diabetic Retinopathy Clinical Research Network. Factors associated with changes in visual acuity and central subfield thickness at 1 year after treatment for diabetic macular edema with ranibizumab. Arch Ophthalmol 2012;130:1153-61.

7. Boyer DS, Yoon YH, Belfort R Jr, Bandello F, Maturi RK, Augustin AJ, et al. Threeyear, randomized, sham-controlled trial of dexamethasone intravitreal implant in patients with diabetic macular edema. Ophthalmology 2014;121:1904-14.

8. Campochiaro PA, Brown DM, Pearson A, Chen S, Boyer D, Ruiz-Moreno J, et al. Sustained delivery fluocinolone acetonide vitreous inserts provide benefit for at least 3 years in patients with diabetic macular edema. Ophthalmology 2012;119:2125-32.
9. Kook D, Wolf A, Kreutzer T, Neubauer A, Strauss R, Ulbig M, et al. Long-term effect of intravitreal bevacizumab (avastin) in patients with chronic diffuse diabetic macular edema. Retina 2008;28:1053-60.

10. Roohipoor R, Sharifian E, Ghassemi F, Riazi-Esfahani M, Karkhaneh R, Fard Ma, et al. Choroidal thickness changes in proliferatıve diabetic retinopathy treated with panretinal photocoagulation versus panretinal photocoagulation with intravitreal bevacizumab. Retina 2016;36:1997-2005.

11. Kim M, Cho YJ, Lee CH, Lee SC. Effect of intravitreal dexamethasone implant on retinal and choroidal thickness in refractory diabetic macular oedema after multiple anti-VEGF injections. Eye (Lond) 2016;30:718-25

12. McLeod DS, Lutty GA. High-resolution histologic analysis of the human choroidal vasculature. Invest Ophthalmol Vis Sci 1994;35:3799-811.

13. Lutty GA. Effects of diabetes on the eye. Invest Ophthalmol Vis Sci 2013;54:81-7.

14. Melancia D, Vicente A, Cunha JP, Abegão Pinto L, Ferreira J. Diabetic choroidopathy: a review of the current literature. Graefes Arch Clin Exp Ophthalmol 2016;254:145361.

15. Cao J, McLeod S, Merges CA, Lutty GA. Choriocapillaris degeneration and related pathologic changes in human diabetic eyes. Arch Ophthalmol 1998;116:589-97.

16. Nagaoka T, Kitaya N, Sugawara R, Yokota H, Mori F, Hikichi T, et al. Alteration of choroidal circulation in the foveal region in patients with type 2 diabetes. $\mathrm{Br} \mathrm{J}$ Ophthalmol 2004;88:1060-3

17. Spaide RF. Enhanced depth imaging optical coherence tomography of retinal pigment epithelial detachment in age related macular degeneration. Am J Ophthalmol 2009;147:644-52.

18. Cheng H, Kaszubski PA, Hao H, Saade C, Cunningham C, Freund KB, et al. The Relationship between Reticular Macular Disease and Choroidal Thickness. Curr Eye Res 2016;41:1492-7.

19. Chung YR, Kim JW, Kim SW, Lee K. Choroidal thickness in patients with central serous chorioretinopathy: assessment of Haller and Sattler layers. Retina 2016;36:1652-7

20. Rayess N, Rahimy E, Ying GS, Bagheri N, Ho AC, Regillo CD, et al. Baseline choroidal thickness as a predictor for response to anti-vascular endothelial growth factor therapy in diabetic macular edema. Am J Ophthalmol 2015;159:85-91.

21. Regatieri CV, Branchini L, Carmody J, Fujimoto JG, Duker JS. Choroidal thickness in patients with diabetic retinopathy analyzed by spectral-domain optical coherence tomography. Retina 2012;32:563-8

22. Kim JT, Lee DH, Joe SG, Kim JG, Yoon YH. Changes in choroidal thickness in relation to the severity of retinopathy and macular edema in type 2 diabetic patients. Invest Ophthalmol Vis Sci 2013;54:3378-84.

23. Ozdogan Erkul S, Kapran Z, Uyar OM. Quantitative analysis of subfoveal choroidal thickness using enhanced depth imaging optical coherence tomography in normal eyes. Int Ophthalmol 2014;34:35-40.

24. Okamoto M, Matsuura T, Ogata N. Effects of panretinal photocoagulation on choroidal thickness and choroidal blood flow in patients with severe nonproliferative diabetic retinopathy. Retina 2016;36:805-11

25. Sonoda S, Sakamoto T, Yamashita T, Otsuka H, Shirasawa M, Kakiuchi N, et al. Effect of intravitreal triamcinolone acetonide or bevacizumab on choroidal thicknes in eyes with diabetic macular edema. Invest Ophthalmol Vis Sci 2014;55:3979-85.

26. Haller JA, Kuppermann BD, Blumenkranz MS, Williams GA, Weinberg DV, Chou $\mathrm{C}$, et al. Randomized controlled trial of an intravitreous dexamethasone drug delivery system in patients with diabetic macular edema. Arch Ophthalmol 2010;128:289-96.

27. Callanan DG, Gupta S, Boyer DS, Ciulla TA, Singer MA, Kuppermann BD, et al Dexamethasone intravitreal implant in combination with laser photocoagulation for the treatment of diffuse diabetic macular edema. Ophthalmology 2013;120:1843-51.

28. Gillies MC, Lim LL, Campain A, Quin GJ, Salem W, Li J, et al. A randomized clinical trial of intravitreal bevacizumab versus intravitreal dexamethasone for diabetic macular edema: the BEVORDEX study. Ophthalmology 2014;121:2473-81.

29. Boyer DS, Faber D, Gupta S, Tabandeh H, Li XY, Liu CC, et al. Dexamethasone intravitreal implant for treatment of diabetic macular edema in vitrectomized patients. Retina 2011;31:915-23. 